\title{
Correlation between physicochemical properties and biological half-life of triazole fungicides in perilla leaf
}

\author{
Sang-Hyeob Lee ${ }^{1}$ (D) $\cdot$ Se-Yeon Kwak ${ }^{1} \cdot$ Jeong-In Hwang ${ }^{1}$ Hyo-Jung Kim ${ }^{1}$ \\ Tae-Hwa Kim ${ }^{2}$ Jang-Eok Kim ${ }^{1}$
}

\section{들깻잎에서 Triazole계 살균제의 생물학적 반감기와 물리화학적 특성과의 상관관계}

이상협 ${ }^{1}$ · 곽세 연 ${ }^{1}$ · 황정 인 ${ }^{1}$ - 김효정 ${ }^{1}$ - 김태화 ${ }^{2}$ - 김장억 ${ }^{1}$

Received: 15 October 2019 / Accepted: 6 November 2019 / Published Online: 31 December 2019

(C) The Korean Society for Applied Biological Chemistry 2019

\begin{abstract}
The biological half-life of pesticides applied on crops is the key indicator for ensuring the safety of agricultural products. The biological half-life is affected by the several factors like growing conditions of the crop, climate, application method, and physicochemical properties of pesticides. In this study, the biological half-life was calculated and the degradation rates of six triazole fungicides sprayed on perilla leaves were evaluated. Moreover, the statistical analysis confirmed the correlation between the biological half-life and physicochemical properties of six triazole pesticides. The recoveries of the six pesticides were between $84.8-104.9 \%$, which satisfied the residual pesticide analysis criteria. The biological half-life of six pesticides sprayed on perilla leaves, calculated using the first-order kinetics model, ranged between 6.4-15.1 days. When the biological half-life and the physicochemical properties were correlated using the principal component analysis: pKa and $\log \mathrm{P}$, the biological half-life was found to be affected by PC1. The correlation coefficient between
\end{abstract}

Jang-Eok Kim $(\bowtie)$

E-mail: jekim@knu.ac.kr

${ }^{1}$ School of Applied Biosciences, Kyungpook National University, Daegu 41566, Republic of Korea

${ }^{2}$ Analysis Technology and Tomorrow, Daegu 41566, Republic of Korea

This is an Open Access article distributed under the terms of the Creative Commons Attribution Non-Commercial License (http://creativecommons. org/licenses/by-nc/3.0/) which permits unrestricted non-commercial use, distribution, and reproduction in any medium, provided the original work is properly cited. biological half-life and physicochemical properties (pKa), calculated by Spearman rank-order correlation, was $R^{2}=-0.928(p<0.01)$. Biological half-life has been shown to correlate with pKa. In conclusion, it can be used as a database for the relationship between biological half-life and physicochemical properties and will contribute to ensure safe supply of agricultural products.

Keywords Biological half-life $\cdot$ Perilla leaf $\cdot$ Physicochemical property $\cdot$ Statistical analysis $\cdot$ Triazole fungicide

\section{서 론}

병해충 방제를 위해 농작물에 살포된 농약은 목적을 달성하여 도 작물에 잔류하여 농산물의 안전성에 문제를 야기할 수 있다 [1]. 이러한 문제를 해결하고자 국가에서는 농산물의 안전성 확 보를 위해 농약의 잔류허용기준(maximum residue limit, MRL) 을 설정하여 유통농산물을 관리하고 있으며, 생산단계 농약잔류 허용기준(pre-harvest residue limit, PHRL)을 적용하여 수확 전 농약의 잔류량을 조사 후 출하 일자의 잔류량을 예측하여 농산 물에 대한 출하 연기 및 폐기처분 등으로 관리하고 있다[2].

PHRL 설정은 작물에 살포된 농약이 일정 농도로 감소하는 특성을 반영한 농약의 감소 예측식인 생물학적 반감기를 이용 하여 산출한다[3]. 이러한 생물학적 반감기는 작물의 생육 조건, 주변 환경 및 농약의 살포방법 등에 영항을 받는다. 예를 들어, 농약의 처리횟수, 처리 간격, 수확 전 처리시기, 작물 특성 및 작물성장에 의한 희석효과 등이 모두 농약 잔류량에 영향을 미 
친다[4-7]. 이러한 생물학적 반감기는 농약의 초기 잔류량과 최 종 잔류량의 차이를 이용하여 농약의 분해 및 소실 속도를 구 하여 산출한다[8].

이와 같이 농약의 분해 및 소실 속도에 가장 큰 영항을 미 치는 초기 부착량과 일차별 농약 소실 경향에 대한 연구는 많 이 진행되고 있다. 하지만 작물체 중 농약의 생물학적 반감기 를 구하고 회귀식을 이용하여 감소계수를 산출하는 연구가 많 았으며[9-11], 다양한 작물 및 다양한 계통의 농약의 연구가 진 행되어 농약 및 작물별 생물학적 반감기에 영향을 미치는 공통 요인을 찾기는 어려웠다. 특히 작물에 따른 농약의 물리화학적 특성 등과 관련된 복합적인 요인에 대한 연구는 부족하였다.

이에 따라 농약의 분해 및 소실에 영향을 미치는 물리화학적 특성 평가가 필요하였다. 따라서 다양한 작물 중 본 연구에 적 절한 작물을 선택하기 위해 시설재배에서 생육하여 기후와 같 은 환경조건의 영향을 적게 받고, 최종 약제 살포 후 연속수확 을 하여 농약의 경시적인 변화를 고려할 수 있는 들깻잎을 선 정하였다. 또한 농약은 작물에 살포시 작물 표면으로부터 침투 하고 작물 내에서 이행성이 있어 다양한 작용기작을 가지고, 치 료효과가 좋아 세계적으로 많이 사용되는 살균제인 triazole계 농약을 선정하였다[12-16]. Triazole계 농약 중 서로 다른 물리 화학적 특성으로 농약 잔류량 차이를 야기할 수 있는 fluquinconazole을 포함한 6종을 선정하였다.

따라서 본 연구에서는 들깻잎에 살포된 triazole계 농약 6종 에 대하여 잔류량의 경시적인 변화를 확인하고 생물학적 반감 기를 산출하여 분해 및 소실 속도를 확인하였다. 또한 생물학 적 반감기에 영향을 미치는 물리화학적 특성을 확인하고자, 통 계분석으로 각 특성별 비중을 확인하여 생물학적 반감기와 농 약의 물리화학적 특성간의 상관관계를 확인하였다.

\section{재료 및 방법}

\section{농약 및 시약}

시험에 사용된 triazole계 살균제 6종 fluqinconazole, hexaconazole, metconazole, myclobutanil, tebuconazole 및 tetraconazole 표준 품의 순도는 98.7-99.0\%로 Dr. Ehrenstorfer GmbH (Augsbug, Germeny)사의 것을 구매하여 사용하였다. 포장시험 중 들깻잎 에 살포한 농약 제품은 파리사드(Fluquinconazole $10 \% \mathrm{SC}$, Bayer Crop Science, Seoul, Korea), 한빛(Hexaconazole 5\% $\mathrm{SC}$, 경농, Seoul, Korea), 살림꾼(Metconazole $20 \% \mathrm{SC}$, 동방아 그로, Seoul, Korea), 시스텐(Myclobutanil 6\% WP, 경농, Seoul, Korea), 호리쿠어(Tebuconazole $25 \% \mathrm{EC}$, 팜한농,
Seoul, Korea), 및 에머넌트(Tetraconazole $12.5 \%$ EW, Bayer Crop Science, Seoul, Korea)이었다. 농약 잔류분석에 사용된 용 매 acetone, acetonitrile, dichloromethane, n-hexane 및 water 는 Burdick \& Jackson(Muskegon, MI, USA)사의 제품이었다. 시료의 정제에 사용된 흡착제 florisil은 Sigma-Aldrich Chemical Co. (MI, USA)사의 60-100 mesh 제품을 $120^{\circ} \mathrm{C}$ 의 건조기에서 8 시간 이상 활성화 시킨 후 사용하였다.

\section{시험 포장 및 약제 살포}

들깻잎의 시험 포장은 경상남도 밀양시 상남면에 위치한 비닐 하우스 재배 포장을 임대하여 실험 하였으며, 품종은 남천이었 다. 구획 및 배치는 $1.4 \mathrm{~m} \times 7.2 \mathrm{~m}$ 크기로 구획하여 $1 \mathrm{~m}$ 의 완충 구를 두고 3 반복으로 배치하였으며 재식 밀도는 $7 \mathrm{~cm} \times 13 \mathrm{~cm}$ 로 파종하여 재배하였다. 시험기간은 2015년 4월부터 2018년 4월 까지 4년에 걸쳐 수행하였으며, hexaconazole, metconazole, myclobutanil 및 fluquinconazole (2016년), tetraconazole (2017 년), tebuconazole (2018년)을 경엽살포 하였다. 약제살포는 fluqinconazole 1,000배, hexaconazole 5,000배, metconazole 3,000 배, myclobutanil 1,500배, tebuconazole 2,000배 및 tetraconazole 1,000 배로 각각 희석하여 $200 \mathrm{~L} / 10 \mathrm{a}$ 의 살포량으로 배부식 분무 기를 사용하여 살포하였다. 살포 시기 및 횟수는 7일 간격으로 3 회 처리하였으며, 수확 시기는 최종 약제 살포 2시간 후 수확 한 0 일차 시료를 포함하여, $1,3,5$ 및 7 일차로 연속 수확하였다.

\section{들깻잎 중 잔류농약분석법}

들깻잎 중 6종 농약의 잔류농약분석 방법은 식품공전 잔류농약 분석법을 참조 및 변형하여 적용 하였다[17]. 들깻잎 시료 $10 \mathrm{~g}$ 에 $80 \mathrm{~mL}$ acetone 및 acetonitrile을 첨가하여 homogenizer에서 3 분간 $12,000 \mathrm{rpm}$ 으로 고속마쇄 추출하였으며, 추출액은 Celite 545 로 흡인여과한 후 dichloromethane으로 2회 액액분배하였다. 액액분배된 추출액은 감압농축한 후 hexane으로 재용해하여 정 제과정에 사용하였다.

6종의 농약 중 5종(tebuconazole, fluquinconazole, metconazole, hexaconazole 및 myclobutanil)의 정제과정은 glass column (16 $\mathrm{mm}$, I.D.)에 활성화 시킨 $10 \mathrm{~g}$ 의 florisil과 sodium sulfate anhydrous $(1 \mathrm{~cm}$ 높이)를 hexane으로 습식 충전한 것을 사용하 였다. Tebuconazole, fluquinconazole 및 metconazole의 경우 $100 \mathrm{~mL}$ hexane/acetone $(90 / 10, \mathrm{v} / \mathrm{v})$ 으로 1차 용출시켜 그 용출 액을 흘려버린 후, $70 \mathrm{~mL}$ hexane/acetone $(80 / 20, \mathrm{v} / \mathrm{v})$ 으로 2 차 용출시켜 그 용출액을 분취하여 감압농축하였으며, hexaconazole 시료의 정제는 $90 \mathrm{~mL}$ hexane/ethyl acetate $(70 / 30, \mathrm{v} / \mathrm{v})$ 으로 1 차 용출시켜 그 용출액을 흘려버린 후, $80 \mathrm{~mL}$ hexane/ethyl

Table 1 Physicochemical properties of 6 triazole fungicides

\begin{tabular}{|c|c|c|c|c|c|}
\hline Pesticide & $\begin{array}{l}\text { Molecular weight } \\
\text { (g/mol) }\end{array}$ & $\begin{array}{c}\log \mathrm{P} \\
\left(\mathrm{pH} 7,20^{\circ} \mathrm{C}\right)\end{array}$ & $\begin{array}{l}\text { Solubility in water } \\
\left(20^{\circ} \mathrm{C}, \mathrm{mg} / \mathrm{L}\right)\end{array}$ & $\begin{array}{c}\text { Vapour pressure } \\
\left(20^{\circ} \mathrm{C}, \mathrm{mPa}\right)\end{array}$ & $\begin{array}{c}\text { Dissociation constant } \\
\left(25^{\circ} \mathrm{C}\right)\end{array}$ \\
\hline Fluquinconazole & 376.17 & 3.24 & 1.15 & 6.40.E-06 & 0.9 \\
\hline Hexaconazole & 314.21 & 3.9 & 18 & 1.80.E-02 & 2.3 \\
\hline Metconazole & 319.83 & 3.85 & 30.4 & 2.10.E-05 & 11.38 \\
\hline Myclobutanil & 288.78 & 2.94 & 132 & 1.98.E-01 & 2.3 \\
\hline Tebuconazole & 307.82 & 3.7 & 36 & 1.30.E-03 & 5 \\
\hline Tetraconazole & 372.15 & 3.56 & 156.6 & 1.80.E-01 & 0.65 \\
\hline
\end{tabular}


Table 2 HPLC-UVD and GC-ECD conditions for the residue analysis of 6 triazole fungicides in perilla leaf

\begin{tabular}{|c|c|c|c|c|}
\hline \multicolumn{2}{|c|}{ LC Condition } & Fluquinconazole & Metconazole & Tebuconazole \\
\hline \multicolumn{2}{|l|}{ Model } & \multicolumn{3}{|c|}{ Shimadzu Prominence } \\
\hline \multicolumn{2}{|l|}{ Column } & \multicolumn{3}{|c|}{ SHISEIDO C18 [150 mm (L)×3.0 mm (i.d)., $3.0 \mu \mathrm{m}]$} \\
\hline \multicolumn{2}{|c|}{ Column Temp. } & \multicolumn{3}{|c|}{$40^{\circ} \mathrm{C}$} \\
\hline \multicolumn{2}{|l|}{ Mobile phase } & Acetonitrile/water (47/53) & Acetonitrile/water $(50 / 50)$ & Acetonitrile/water (60/40) \\
\hline \multicolumn{2}{|l|}{ Wavelength } & $243 \mathrm{~nm}$ & $221 \mathrm{~nm}$ & $254 \mathrm{~nm}$ \\
\hline \multicolumn{2}{|c|}{ Injection volume } & $10 \mu \mathrm{L}$ & $20 \mu \mathrm{L}$ & $20 \mu \mathrm{L}$ \\
\hline \multicolumn{2}{|c|}{ Retention time } & $17.7 \mathrm{~min}$ & $21.3 \mathrm{~min}$ & $17.5 \mathrm{~min}$ \\
\hline \multicolumn{2}{|c|}{ GC Condition } & Tetraconazole & Hexaconazole & Myclobutanil \\
\hline \multicolumn{2}{|c|}{ Instrument } & \multicolumn{3}{|c|}{ Shimadzu GC 2010} \\
\hline \multicolumn{2}{|l|}{ Detector } & \multicolumn{3}{|c|}{$\mathrm{ECD}$} \\
\hline \multicolumn{2}{|l|}{ Column } & \multicolumn{3}{|c|}{ DB-5 [0.25 $\mathrm{mm}$ i.d $\times 30 \mathrm{~m}, 0.25 \mu \mathrm{m}$ film thickness (J\&W Scientific, USA)] } \\
\hline \multirow{3}{*}{ Temperature } & Column & $\begin{array}{l}60^{\circ} \mathrm{C}(2 \mathrm{~min}) \rightarrow 15^{\circ} \mathrm{C} / \mathrm{min} \rightarrow 200{ }^{\circ} \mathrm{C} \\
(10 \mathrm{~min}) \rightarrow 15^{\circ} \mathrm{C} / \mathrm{min} \rightarrow 280^{\circ} \mathrm{C}(5 \mathrm{~min})\end{array}$ & $\begin{array}{l}100^{\circ} \mathrm{C}(2 \mathrm{~min}) \rightarrow 10^{\circ} \mathrm{C} / \mathrm{min} \rightarrow 200 \\
(5 \mathrm{~min}) \rightarrow 10^{\circ} \mathrm{C} / \mathrm{min} \rightarrow 280^{\circ} \mathrm{C}(10\end{array}$ & $\begin{array}{l}\mathrm{C}(2 \mathrm{~min}) \rightarrow 10^{\circ} \mathrm{C} / \mathrm{min} \rightarrow 200^{\circ} \mathrm{C} \\
\text { nin }) 10^{\circ} \mathrm{C} / \mathrm{min} \rightarrow 280^{\circ} \mathrm{C}(5 \mathrm{~min})\end{array}$ \\
\hline & Detector & & $280{ }^{\circ} \mathrm{C}$ & \\
\hline & Injector & & $260{ }^{\circ} \mathrm{C}$ & \\
\hline \multicolumn{2}{|l|}{ Gas flow rate } & & $\mathrm{N}_{2} 1 \mathrm{~mL} / \mathrm{min}$ & \\
\hline \multicolumn{2}{|c|}{ Injection Volumn } & & $1.0 \mu \mathrm{L}$ & \\
\hline \multicolumn{2}{|c|}{ Retention time } & $19.5 \mathrm{~min}$ & $21.3 \mathrm{~min}$ & $22.1 \mathrm{~min}$ \\
\hline
\end{tabular}

acetate $(50 / 50, \mathrm{v} / \mathrm{v})$ 으로 2 차 용출시켜 그 용출액을 분취하여 농 축하였다. Myclobutanil 시료의 정제는 $70 \mathrm{~mL}$ hexane/acetone $(90 / 10, v / v)$ 으로 1 차 용출시켜 그 용출액을 흘려버린 후, 70 $\mathrm{mL}$ hexane/acetone $(70 / 30, \mathrm{v} / \mathrm{v})$ 으로 2차 용출시켜 그 용출액을 분취하여 농축하였다. 상기의 5종 농약 중 fluquinconazole, metconazole 및 tebuconazole은 농축 직후 잔사를 acetonitrile 2 및 $4 \mathrm{~mL}$ 에 재용해한 뒤 $20.0 \mu \mathrm{L}$ 씩 HPLC-UVD에 주입하여 Table 2와 같은 조건으로 분석하였다. 해당 분석 조건으로 나타 난 chromatogram상의 peak area를 표준검량선과 비교하여 잔류 량을 산출하였다.

Tetraconazole 시료의 경우 florisil SPE cartridge $(1 \mathrm{~g}, 6 \mathrm{~mL})$ 를 정제에 사용하였으며, SPE cartridge에 $10 \mathrm{~mL}$ 의 hexane으로 씻어 내린 후 추출액을 loading하였다. 시료의 정제는 $10 \mathrm{~mL}$ hexane으로 1차 용출시켜 그 용출액을 흘려버린 후, $10 \mathrm{~mL}$ hexane/acetone $(8 / 2, \mathrm{v} / \mathrm{v})$ 으로 2 차 용출시켜 그 용출액을 분취 하여 감압농축 하였다. Tetraconazole, hexaconzole 및 myclobutanil 은 농축 직후 잔사를 acetone $2 \mathrm{~mL}$ 에 재용해한 뒤 $1.0 \mu \mathrm{L}$ 씩 $\mathrm{GC}-\mathrm{ECD}$ 에 주입하여 Table 2와 같은 조건으로 분석하였다. 해 당 분석 조건으로 나타난 chromatogram상의 peak area를 표준 검량선과 비교하여 잔류량을 산출하였다.

\section{생물학적 반감기 산출 및 통계처리}

들깻잎 중 농약 6종의 생물학적 반감기 $(T)$ 는 first-order kinetics model을 적용하여 아래의 식에 따라 산출하였다.

$$
\begin{aligned}
& C_{t}=C_{0} e^{-k t} \\
& \frac{1}{2} C_{0}=C_{0} e^{-k t} \\
& T=\frac{\ln (2)}{k}
\end{aligned}
$$

위 식에서 $C_{0}$ 는 농약의 초기 잔류량 $(\mathrm{mg} / \mathrm{kg}), t$ 는 경과일자, $k$ 는 감소상수를 나타내며 $C_{t}$ 는 $t$ 시간 경과 후 농약의 잔류량 $(\mathrm{mg} / \mathrm{kg})$ 을 나타낸다.

상기의 식으로 산출된 들깻잎 중 농약의 생물학적 반감기와 각 농약의 물리화학적 특성과의 관계를 확인하고자 통계분석을 하였다. 통계분석은 SPSS 18.0 ver (SPSS Inc., Chicago, IL, USA) 통계프로그램을 이용하여, 주성분 분석 및 이변량 상관계 수로 통계처리 하였다. 총 8 개의 변수를 설정하여 평가하였으 며, 그 중 종속변수는 초기잔류량(initial concentration, IC) 및 농약의 생물학적 반감기(half of residue level, $\mathrm{RL}_{50}$ ), 독립변수 는 5항목의 물리화학적 특성 및 농약 살포액의 약량(active ingredient, $\mathrm{AI}$ )으로 총 7개의 변수를 설정하였다. 5항목의 물리 화학적 특성은 분자량(molecular weight, $\mathrm{MW}), \log \mathrm{P}$, 물에 대한 용해도(solubility in water, $\mathrm{S}_{\mathrm{W}}$ ), 증기압(vapor pressure, $\mathrm{P}_{\mathrm{V}}$ ), 및 산해리상수 지수(dissociation constant, $\mathrm{pKa}$ )로 설정하였 으며, 그 값은 University of Hertfordshire의 pesticide properties database (PPDB)의 자료를 인용하여 Table 1과 같이 확인 되었다.

\section{결과 및 고찰}

\section{잔류농약분석법의 검중}

상기에 기술한 6 종의 잔류농약분석법의 신뢰성을 위해 분석법 을 검증하였다. 정량분석을 위해 표준검량선을 작성하였으며, 각 농약의 직선성의 상관계수 $\left(R^{2}\right)$ 는 0.9990-0.9999로 양호하게 나 타났다. 6종 농약의 분석법 정량한계는 $0.02-0.04 \mathrm{mg} / \mathrm{kg}$ 이였으 며, 회수율 시험의 농도 수준은 정량한계 10 배 및 50 배의 2 수 준에서 시험하였다. 시험농약의 회수율시험 결과는 Table 3 과 같이 fluqinconazole 86.0-90.8\%, hexaconazole 83.7-94.0\%, 
Table 3 Recoveries for analytical methods of of 6 triazole fungicides in preilla leaf

\begin{tabular}{|c|c|c|c|c|c|c|c|}
\hline \multirow{2}{*}{ Pesticide } & \multirow{2}{*}{$\begin{array}{c}\text { Fortification } \\
\text { level }(\mathrm{mg} / \mathrm{kg})\end{array}$} & \multicolumn{4}{|c|}{ Recovery (\%) } & \multirow{2}{*}{$\begin{array}{c}\left.\mathrm{MDA}^{\mathrm{c}}\right) \\
\text { (ng) }\end{array}$} & \multirow{2}{*}{$\begin{array}{c}\left.\mathrm{LOD}^{\mathrm{d}}\right) \\
(\mathrm{mg} / \mathrm{kg})\end{array}$} \\
\hline & & 1 & 2 & 3 & $\mathrm{Mean}^{\mathrm{a})} \pm \mathrm{SD}^{\mathrm{b})}$ & & \\
\hline \multirow{2}{*}{ Fluquinconazole } & 0.2 & 90.8 & 90.8 & 90.4 & $90.7 \pm 0.3$ & \multirow{2}{*}{4.0} & \multirow{2}{*}{0.02} \\
\hline & 1.0 & 86.7 & 86.0 & 86.8 & $86.5 \pm 0.4$ & & \\
\hline \multirow{2}{*}{ Hexaconazole } & 0.4 & 83.7 & 94.0 & 92.8 & $90.2 \pm 5.6$ & \multirow{2}{*}{0.2} & \multirow{2}{*}{0.04} \\
\hline & 2.0 & 85.0 & 84.8 & 85.6 & $85.1 \pm 0.4$ & & \\
\hline \multirow{2}{*}{ Metconazole } & 0.4 & 97.5 & 97.6 & 97.1 & $97.4 \pm 0.3$ & \multirow{2}{*}{0.2} & \multirow{2}{*}{0.04} \\
\hline & 2.0 & 96.8 & 98.0 & 98.2 & $97.6 \pm 0.7$ & & \\
\hline \multirow{2}{*}{ Myclobutanil } & 0.4 & 92.8 & 86.7 & 91.3 & $90.3 \pm 3.2$ & \multirow{2}{*}{0.2} & \multirow{2}{*}{0.04} \\
\hline & 2.0 & 85.5 & 87.0 & 86.6 & $86.3 \pm 0.8$ & & \\
\hline \multirow{2}{*}{ Tebuconazole } & 0.4 & 104.9 & 96.7 & 101.6 & $101.0 \pm 4.1$ & \multirow{2}{*}{4.0} & \multirow{2}{*}{0.04} \\
\hline & 2.0 & 85.6 & 86.8 & 88.5 & $87.0 \pm 1.5$ & & \\
\hline \multirow{2}{*}{ Tetraconazole } & 0.4 & 94.1 & 92.9 & 88.9 & $95.7 \pm 3.7$ & \multirow{2}{*}{0.2} & \multirow{2}{*}{0.04} \\
\hline & 2.0 & 98.4 & 94.7 & 92.6 & $95.2 \pm 2.9$ & & \\
\hline
\end{tabular}

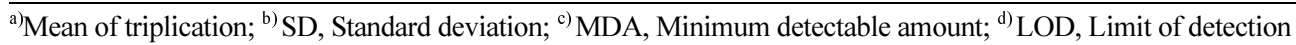

Table 4 Residual amounts of 6 triazole fungicides in perilla leaf after final application

\begin{tabular}{|c|c|c|c|c|c|c|c|}
\hline \multirow{3}{*}{ Pesticide } & \multirow{3}{*}{$\begin{array}{l}\text { Amount of } \\
\text { active ingredient } \\
(\mathrm{kg} \text { a.i./10a) }\end{array}$} & \multirow{3}{*}{$\begin{array}{l}\text { Number of } \\
\text { application }\end{array}$} & \multicolumn{5}{|c|}{ Residual amount $^{\text {a) }}(\mathrm{mg} / \mathrm{kg}) \pm \mathrm{SD}^{\mathrm{b})}$} \\
\hline & & & \multicolumn{5}{|c|}{ Days after final application } \\
\hline & & & 0 & 1 & 3 & 5 & 7 \\
\hline Fluquinconazole & 0.020 & 3 & $23.55 \pm 0.01$ & $21.70 \pm 0.01$ & $21.44 \pm 0.01$ & $18.70 \pm 0.01$ & $15.30 \pm 0.00$ \\
\hline Hexaconazole & 0.002 & 3 & $1.11 \pm 0.06$ & $0.80 \pm 0.05$ & $0.62 \pm 0.00$ & $0.60 \pm 0.02$ & $0.53 \pm 0.02$ \\
\hline Metconazole & 0.013 & 3 & $5.69 \pm 0.00$ & $3.78 \pm 0.03$ & $3.36 \pm 0.02$ & $2.92 \pm 0.00$ & $2.52 \pm 0.05$ \\
\hline Myclobutanil & 0.008 & 3 & $5.70 \pm 0.01$ & $4.96 \pm 0.02$ & $3.95 \pm 0.06$ & $3.93 \pm 0.00$ & $2.96 \pm 0.07$ \\
\hline Tebuconazole & 0.025 & 3 & $7.13 \pm 0.02$ & $5.43 \pm 0.01$ & $4.82 \pm 0.04$ & $3.73 \pm 0.01$ & $3.17 \pm 0.06$ \\
\hline Tetraconazole & 0.025 & 3 & $11.86 \pm 0.05$ & $10.44 \pm 0.01$ & $9.43 \pm 0.03$ & $9.16 \pm 0.01$ & $8.28 \pm 0.04$ \\
\hline
\end{tabular}

a) Mean of triplication; ${ }^{\text {b) }} \mathrm{SD}$, Standard deviation

metconazole 96.8-98.2\%, myclobutanil $85.5-92.8 \%$, tebuconazole $85.6-104.9 \%$ 및 tetraconazole 88.9-98.4\%로 나타났으며, 모두 $10 \%$ 이내의 상대표준편차로 나타나 잔류농약분석법 기준인 회 수율 70-120\% 및 상대표준편차 $10 \%$ 이내를 만족하였다.

\section{들깻잎 중 농약 잔류특성}

들깻잎에 최종 약제 살포 후 $0,1,3,5$ 및 7일차에 수확을 하 여 농약의 잔류량의 감소율을 확인 하였다. Triazole계 농약 6 종에 대한 농약의 잔류량은 Table 4와 같이 나타났다. Fluquinconazole의 초기잔류량 $(0$ 일차)은 평균 $23.55 \mathrm{mg} / \mathrm{kg}$ 으로 나타났으며, 7일 후 평균 $15.30 \mathrm{mg} / \mathrm{kg}$ 이였다. Hexaconazole은 0 일차 $1.11 \mathrm{mg} / \mathrm{kg}$ 에서 7 일차 $0.53 \mathrm{mg} / \mathrm{kg}$, metconazole은 0 일차 $5.69 \mathrm{mg} / \mathrm{kg}$ 에서 7 일차 $2.52 \mathrm{mg} / \mathrm{kg}$, myclobutanil은 0 일차 5.70 $\mathrm{mg} / \mathrm{kg}$ 에서 7일차 $2.96 \mathrm{mg} / \mathrm{kg}$, tebuconazole은 0 일차 $7.13 \mathrm{mg}$ / $\mathrm{kg}$ 에서 7일차 $3.17 \mathrm{mg} / \mathrm{kg}$, tetraconazole은 0 일차 $11.86 \mathrm{mg} / \mathrm{kg}$ 에 서 7 일차 $8.28 \mathrm{mg} / \mathrm{kg}$ 로 나타나 최종 약제 살포 후 시간이 지날 수록 점차 감소하는 경향이 나타났다.

최종 약제 살포 후 2 시간 후인 0 일차 시료의 잔류량은 6 종 농약이 각기 달랐다. Fluquinconazole을 살포한 0 일차 시료에서 $23.55 \mathrm{mg} / \mathrm{kg}$ 으로 가장 높게 나타났고, hexaconazole을 살포한 시 료에서는 $1.11 \mathrm{mg} / \mathrm{kg}$ 으로 가장 낮았다. 본 실험에서는 안전사용
기준에 따라 살포하였기 때문에, 각 농약 별 잔류량이 다른 것 으로 나타났다. Table 4에 제시한 바와 같이 실제 농약 살포액 의 약량을 고려하였을 때, fluquinconazole은 hexaconazole에 비 해 이론적으로 10 배 더 많은 양이 살포되었다. 하지만, 잔류량 의 차이는 21.2 배 정도 높은 것으로 나타나 살포된 약량과 0 일 차 시료의 잔류량의 비율이 다른 경향을 보였다. 농약 살포액 조제시 fluquinconazole의 희석배수는 1,000 배이며, hexaconazole 의 희석배수는 5,000 배로 살포액의 희석농도는 5 배 차이 났다. 이는 두 농약이 같은 제형이라도 농약 살포액의 약량, 살포액 량 및 희석배수에 따라 초기 부착량의 차이가 나타나는 것이라 판단된다[18,19]. 반면에 tebuconazole 및 tetraconazole의 경우 농약 살포액의 약량이 $0.025 \mathrm{~kg}$ a.i./10a로 동일하지만, tebuconazole 의 경우 초기 잔류량이 $7.13 \mathrm{mg} / \mathrm{kg}$ 이며, tetraconazole은 11.86 $\mathrm{mg} / \mathrm{kg}$ 으로 $4.73 \mathrm{mg} / \mathrm{kg}$ 의 초기 잔류량이 차이가 난다. 이는 사 용된 농약의 제형이 tebuconazole은 유제, tetraconazole은 유탁 제로 두 농약간의 제형이 달라 농약의 제형이 작물에 대한 농 약 부착량에 영향을 주는 것으로 판단된다[20,21].

Hexaconazole, metconazole 및 tebuconazole의 최종 약제 살 포 후 초기 잔류량 대비 7일차 잔류량의 감소율은 각 52.3, 55.7 및 $55.5 \%$ 로 나머지 4종에 비해 높았다. Myclobutanil은 $48.1 \%$ 감소하였으며, fluquinconazole 및 tetraconazole은 각 
Table 5 Biological half-life of 6 triazole pesticides in perilla leaf under greenhouse condition

\begin{tabular}{lccc}
\hline \hline \multicolumn{1}{c}{ Pesticide } & Regression curves ${ }^{\mathrm{a})}$ & $\begin{array}{c}\text { Correlation } \\
\text { coefficient } \\
\left(R^{2}\right)\end{array}$ & $\begin{array}{c}\text { Half-life } \\
\text { (days) }\end{array}$ \\
\hline Fluquinconazole & $\mathrm{Y}=23.8696 \mathrm{e}^{-0.0566 \mathrm{x}}$ & 0.9174 & 12.2 \\
Hexaconazole & $\mathrm{Y}=0.9531 \mathrm{e}^{-0.0939 \mathrm{x}}$ & 0.8357 & 7.4 \\
Metconazole & $\mathrm{Y}=4.8369 \mathrm{e}^{-0.1003 \mathrm{x}}$ & 0.8587 & 6.9 \\
Myclobutanil & $\mathrm{Y}=5.5020 \mathrm{e}^{-0.0848 \mathrm{x}}$ & 0.9368 & 8.2 \\
Tebuconazole & $\mathrm{Y}=6.6063 \mathrm{e}^{-0.1088 \mathrm{x}}$ & 0.9626 & 6.4 \\
Tetraconazole & $\mathrm{Y}=11.3024 \mathrm{e}^{-0.0459 \mathrm{x}}$ & 0.9224 & 15.1 \\
\hline
\end{tabular}

${ }^{a)}$ Regression curve, based on the first-order kinetics

35.0 및 $30.2 \%$ 의 감소율을 보였다. Triazole계 농약에서 각 성 분에 따라 감소율이 다른 것은 물리화학적 특성에 기반되는 것 이라 판단된다. Ahn 등[22]은 물리화학적 특성 및 작물의 특성 등에 따라 잔류량 차이가 있다고 설명한 것을 바탕으로, Table 1 과 같이 6 종의 농약의 서로 다른 물리화학적 특성이 들깻잎 중 농약의 잔류량 및 감소율에 영향을 미치는 것으로 판단된다. 또한, 이전 연구에 따르면 들깻잎과 같이 짧은 시간에 성장이 빠른 엽경채류의 경우 작물 증체량에 의한 잔류농약의 희석이 크기 때문에 잔류농약의 감소가 나타나는 것으로 판단된다[18].

\section{들깻잎 중 농약의 생물학적 반감기}

Triazole계 농약 6종의 들깻잎 중 농약 잔류량을 바탕으로 firstorder kinetics model에 근거한 각 농약의 $\mathrm{RL}_{50}$ 를 Table 5 와 같이 산출하였다. 각 농약의 감소상수 $(k)$ 는 fluquinconazole 0.0566 , hexaconazole 0.0939 , metconazole 0.1003 , myclobutanil 0.0848 , tebuconazole 0.1088 및 tetraconazole 0.0459 로 나타났 으며, first-order kinetics model의 회귀식 상관계수 $\left(R^{2}\right)$ 는 0.8357-0.9626으로 나타나 통계학적 유의성이 있었다. 감소상수 는 농약의 소실 및 분해 속도를 나타내는 값으로 작을수록 분 해 및 소실 속도가 느리다는 것을 의미한다[23]. 또한 감소상수 는 농약의 잔류량에 많은 영향을 받는데, 농약의 잔류량은 살 포액 조제시 농약의 유효성분 함량, 희석배수 및 살포액량에 의 해 결정이 된다. 본 실험에서는 안전사용기준에 따라 살포하여 각 농약 살포액의 약량이 다르기 때문에 농약간의 비교가 어려 울 것이라 생각할 수 있으나, 「생산단계 농약 잔류허용기준 설 정 및 합리적 운영방안 연구」보고서에 따르면 살포액의 약량 이 증대된다 하더라도 감소상수의 변화는 그다지 크지 않기 때 문에, 살포 변이에 따른 약제 부착량의 수준별 소실속도 변이 는 그 차이를 무시할 수 있는 것으로 보고하였다.

본 연구에서 도출된 각 농약의 감소상수와 반감지수를 이용 하여 $\mathrm{RL}_{50}$ 를 산출하였을 때, 들깻잎 중 농약의 평균 반감기는 9.4일로 나타났다. 6종 농약의 $\mathrm{RL}_{50}$ 는 fluquinconazole 12.2일, hexaconazole 7.4일, metconazole 6.9일, myclobutanil 8.2일, tebuconazole 6.4일 및 tetraconazole 15.1일로 나타나, $\mathrm{RL}_{50}$ 가 가장 긴 농약은 tetraconazole이었으며, tebuconazole이 가장 짧 았다. Tetraconazole과 tebuconazole은 살포액의 약량이 0.025 $\mathrm{kg}$ a.i, $/ 10 \mathrm{a}$ 로 동일하나 $\mathrm{RL}_{50}$ 는 8.7 일이 차이 난다. 이 두 농약 의 $\mathrm{RL}_{50}$ 의 차이를 물리화학적 특성과 비교한 결과 분자량 $(\mathrm{MW})$,
증기압 $\left(\mathrm{P}_{\mathrm{V}}\right)$, 산해리상수 지수 $(\mathrm{pKa})$, 물에 대한 용해도 $\left(\mathrm{S}_{\mathrm{W}}\right)$ 의 차 이가 컸다. Bedos 등[24]에 의하면 상대적으로 증기압이 높은 농약이 낮은 증기압을 가진 농약보단 더 빨리 휘발되었다는 보 고를 하였지만, 본 연구에서는 증기압이 $0.0013 \mathrm{mPa}$ 인 tebuconazole 보다 상대적으로 휘발이 잘되는 $0.18 \mathrm{mPa}$ 인 tetraconazole이 $\mathrm{RL}_{50}$ 가 더 긴 것으로 나타나 상반된 결과를 보 였다. 반면에 Rosendahl 등[25]의 보고에 따르면 휘발이 잘되는 조건인 열대 기후에서 서식하는 열대식물에 살충제 bifenthrin외 4종을 살포하였을 때, 각 농약의 $\mathrm{P}_{\mathrm{V}}$ 와 $\mathrm{RL}_{50}$ 은 직접적인 상관성 이 적으며 농약의 다양한 물리화학적 특성이 $\mathrm{RL}_{50}$ 에 영향을 미 칠 것이라고 보고하여, 본 결과와 부합하는 것으로 나타났다. 따라서 triazole계 농약 6종의 $\mathrm{P}_{\mathrm{V}}$ 와 $\mathrm{RL}_{50}$ 를 비교 하였을 때 $\mathrm{RL}_{50}$ 과 상관성이 적은 것으로 보여, 들깻잎의 생육환경 및 각 농약의 물리화학적 특성이 잔류농약 반감기에 많은 영향을 미 쳤을 것이라 판단된다[26].

농약의 소실에 영향을 미치는 요인 중 대표적인 것은 $\mathrm{S}_{\mathrm{W}}$ 및 농약의 제형이다[27]. 일반적으로 $\mathrm{S}_{\mathrm{W}}$ 가 클수록 관수 및 환경적 요인으로 작물 표면에 부착된 농약이 소실될 가능성이 크기 때 문에 농약 잔류량 및 반감기에 많은 영향을 미친다. 또한, 농약 의 제형도 수화제보다 유제가 부착량이 높고 작물 표면의 침투 성이 크기 때문에 환경적 요인에 소실 가능성 작은 것으로 알 려져 있다. 본 연구에서는 $\mathrm{S}_{\mathrm{W}}$ 가 $156.6 \mathrm{mg} / \mathrm{kg}$ 으로 가장 큰 tetraconazole이 $\mathrm{RL}_{50}$ 가 가장 길어 일반적인 내용과 상반된 것으 로 나타났다. 반면에 $1.15 \mathrm{mg} / \mathrm{kg}$ 으로 $\mathrm{S}_{\mathrm{W}}$ 가 가장 낮은 fluquinconazole 은 12.2 일의 $\mathrm{RL}_{50}$ 가 산출되어 일반적인 내용과 부합한 것으로 보였다. Tetraconazole의 경우 $\mathrm{S}_{\mathrm{W}}$ 가 상대적으로 크지만, 사용된 농약의 제형이 $\mathrm{EW}$ 로 작물 표면의 부착량이 높아 관수 및 환 경적 요인에 소실 가능성이 적어 $\mathrm{RL}_{50}$ 이 긴 것으로 판단된다. $\mathrm{RL}_{50}$ 이 6.4일로 감소속도가 가장 빠른 tebuconazole은 사용된 농약의 제형이 $\mathrm{EC}$ 이며 $\mathrm{Sw}$ 는 $36 \mathrm{mg} / \mathrm{kg}$ 이였다. 두번째로 감소속 도가 빠른 6.9 일의 $\mathrm{RL}_{50}$ 인 metconazole은 제형이 $\mathrm{SC}$ 이며 $\mathrm{S}_{\mathrm{W}}$ 는 $30.4 \mathrm{mg} / \mathrm{kg}$ 으로 나타나 농약의 제형과 $\mathrm{S}_{\mathrm{W}}$ 가 $\mathrm{RL}_{50}$ 에 영향을 주 는 요인이라고 판단하기는 어려웠다. 따라서 전체적인 결과를 봤을 때 각 농약의 제형과 $\mathrm{S}_{\mathrm{W}}$ 는 $\mathrm{RL}_{50}$ 에 영항을 미치는 것으로 단정 짓기는 어렵기 때문에, 그 외 물리화학적 특성을 고려한 복합적인 평가가 필요한 것으로 보인다.

\section{Triazole계 농약 6종의 물리화학적 특성과 생물학적 반감기의 통계분석}

Triazole계 농약 6종의 물리화학적 특성과 $\mathrm{RL}_{50}$ 의 상관성을 확 인하기 위하여, 주성분 분석(principal components analysis, $\mathrm{PCA}$ )을 하였다. $\mathrm{PCA}$ 는 분포되어 있는 데이터들의 주성분 (principal component)을 찾아주는 통계적 기법 중 하나로써, 여 러 개의 많은 변수들을 몇 개의 설명력이 높은 변수로 축약하 여 서로 상관되어 변수들간의 관계를 확인하는데 시각적으로 파 악하는 방법이다[28,29].

Fig. 1(A)는 주성분 분석의 제 1주성분(PC1), 제 2주성분 (PC2)로 구분된 물리화학적 특성으로 분포를 나타내고 있으며, Fig. $1(\mathrm{~B})$ 는 각 주성분 분석에 기여한 각 농약의 위치를 나타내 고 있다. $\mathrm{PC} 1$ 과 $\mathrm{PC} 2$ 의 변동은 46.0 과 $29.0 \%$ 로 설명해 주어 총 변동의 $75.0 \%$ 가 설명되었다. 일반적으로 주성분 수가 2 개일 때 총 변동 설명율이 $74 \%$ 이상일 경우 충분한 설명력을 가진다 

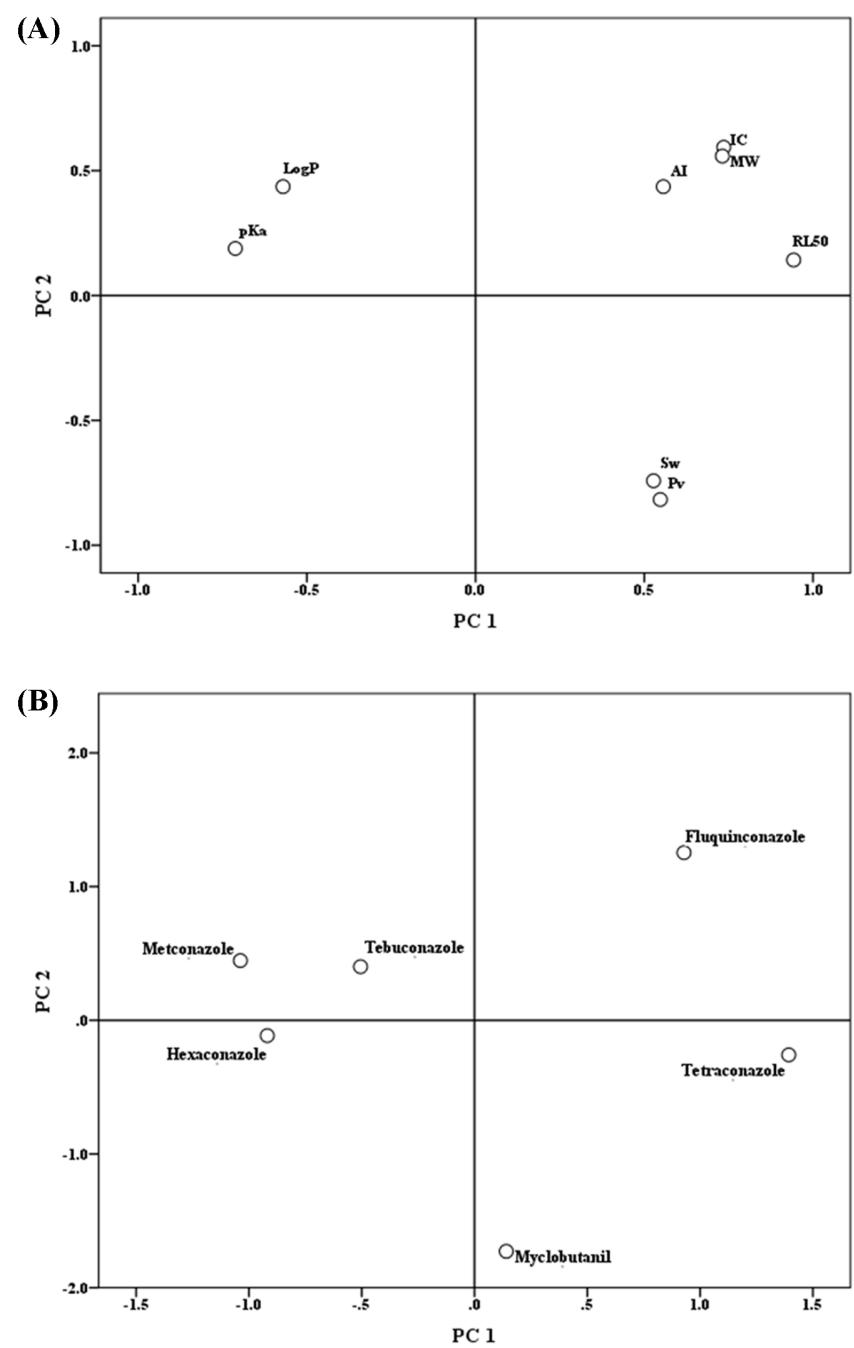

Fig. 1 Principal component analysis (PCA) of the physicochemical properties of 6 triazole fungicides and $\mathrm{RL}_{50}$ in perilla leaf. In (A)), PCA loadings plot of $\mathrm{PC} 1$ vs. PC2 from $\mathrm{RL}_{50}$ in perilla leaf. In (B)), PCA scores plot obtained from $\mathrm{RL}_{50}$ in perilla leaf

고 판단한다[28,29]. Fig. 1(A)에서 $\mathrm{RL}_{50}$ 은 $\mathrm{PC} 1$ 에 영향을 많이 받는 것으로 나타났으며, $\mathrm{PC} 1$ 에 영향을 받는 물리화학적 특성 은 $\mathrm{MW}, \mathrm{pKa}, \log \mathrm{P}$ 였으며, $\mathrm{S}_{\mathrm{W}}$ 및 $\mathrm{P}_{\mathrm{V}}$ 는 $\mathrm{PC} 2$ 를 설명하는 인 자이기 때문에 $\mathrm{RL}_{50}$ 과의 상관성은 떨어진다. $\mathrm{RL}_{50}$ 은 $\mathrm{MW}$ 와 양 의 관계를 가지며, $\mathrm{pKa}$ 및 $\log \mathrm{P}$ 는 음의 상관성을 가진다. 따 라서, $\mathrm{RL}_{50}$ 은 $\mathrm{pKa}$ 및 $\log \mathrm{P}$ 가 클수록 소실속도가 빠른 것을 예상할 수 있다. 그 중 Fig. 1(B)와 같이 metconazole 및 hexaconazole 은 $\mathrm{PC} 1$ 에서 음의 영향을 받기 때문에 분해속도가 빠를 것이며, tetraconazole 및 fluquinconazole은 상대적으로 분해속도가 느릴 것이라 판단된다.

$\mathrm{PCA}$ 에서 $\mathrm{pKa}, \log \mathrm{P}$ 및 $\mathrm{MW}$ 가 $\mathrm{RL}_{50}$ 사이의 상관관계가 발견되었지만, 통계적으로 유의한 수준의 상관성을 설명하기 위 해 이변량 상관분석을 실시하였다. 본 연구에서 사용된 농약은 6종이기 때문에 샘플수가 적어 통계적 오류가 일어나기 쉽기 때 문에, 상관분석을 하기 전 각 변수값의 정규성 검정을 실시하
여 모수 통계에 적합한 데이터인지 검증하였다. 정규성 검정에 는 작은 샘플 수에 적용하는 Shapiro-wilk 검정을 실시하였으며, 그 결과 8 항목의 변수 중 7 항목인 $\mathrm{AI}, \mathrm{MW}, \log \mathrm{P}, \mathrm{S}_{\mathrm{W}}, \mathrm{pKa}$, $\mathrm{RL}_{50}$ 및 $\mathrm{IC}$ 가 모두 유의확률 $(\mathrm{P}) \geq 0.05$ 이상으로 나타나 정규성 을 만족하였다. 반면에, $\mathrm{P}_{\mathrm{V}}$ 의 $\mathrm{P}$ 는 0.007 로 나타나 정규성에 만 족하지 않았다.

이변량 상관계수를 산출하는 모델은 pearson linear correlation coefficient (PLCC), spearman rank-order correlation coefficient (SROCC) 및 kendall rank-order correlation coefficient가 주로 사용된다. 일반적으로 상관성을 파악하기 위해 가장 많이 사용 되는 상관계수는 $\mathrm{PLCC}$ 와 $\mathrm{SROCC}$ 이다. $\mathrm{PLCC}$ 같은 경우 두 변수 간에 선형성이 얼마나 강한지를 측정하기 위함이고, SROCC는 두 변수간의 단조성을 평가하기 위해 사용된다. 따 라서, $\mathrm{RL}_{50}$ 과 농약의 물리화학적 특성상 선형성보다는 단조성 에 적합하여 Table 6과 같이 SROCC를 이용하여 상관계수를 산출하였다. 또한, $\mathrm{RL}_{50}$ 과 변수간의 관계를 시각적으로 확인하 기 위하여 Fig. 2와 같이 산점도로 나타내었다. 그 결과 $\mathrm{RL}_{50}$ 과 $\mathrm{pKa}$ 의 상관계수가 -0.928 로 매우 높은 음의 상관관계가 나 타났으며, $p<0.01$ 로 유의확률이 높았다. IC 및 $\mathrm{MW}$ 의 $R^{2}$ 는 0.543 의 양의 약한 상관관계, $\log \mathrm{P}$ 는 -0.543 으로 음의 약한 상관관계로 나타났다[28]. 이러한 결과는 Fig. 1처럼 주성분 분 석과 연관성이 나타나, 해당 물리화학적 특성이 $\mathrm{RL}_{50}$ 과 상관성 이 있는 것으로 판단된다.

농약의 물리화학적 특성 중 $\mathrm{pKa}, \mathrm{MW}$ 및 $\log \mathrm{P}$ 는 작물의 잔류량에 많은 영향을 미친다[30-32]. 작물 엽면에 부착된 농약 은 잎의 기공 및 큐티클 층을 통하여 작물체 내로 침투할 수 있고 침투한 농약은 물리화학적 특성에 따라 체관부 및 물관부 로 통해 이동한다[33]. 침투된 triazole계의 농약은 대부분 물관 부에 분포하여, 작물체 전체로 이동될 수 있으며, 침투되는 정 도는 $\mathrm{pKa}$ 및 $\log \mathrm{P}$ 값에 따라 결정된다[34]. $\log \mathrm{P}$ 는 약 3.2 이하 및 $\mathrm{pKa}$ 는 낮을수록 침투 되는 정도가 크다. LehoczkiKrsjak 등[35] 및 Schermerhom 등[36]의 연구에 따르면, tebuconazole $(\log \mathrm{P}=3.7, \mathrm{pKa}=5.0)$ 보다 flutriafol $(\log \mathrm{P}=2.3, \mathrm{pKa}=2.3)$ 이 침투되는 정도가 컸으며, flutriafolo triazole계 농약 중 가장 침 투성이 좋은 농약이라고 보고하였다. 위의 연구를 참고하였을 때, 본 연구에서 사용된 농약 중 침투가능성이 가장 적은 농약 은 metconazole $(\log \mathrm{P}=3.85, \mathrm{pKa}=11.38)$ 및 tebuconazole $(\log$ $\mathrm{P}=3.7, \mathrm{pKa}=5.0$ )이었다. 두 농약은 침투가능성이 적어, 표면에 잔류할 가능성이 높고 식물체 내에서 이동성이 적기 때문에 작 물의 생육환경(관수, 기온, 습도 등)에 의해서 분해 및 소실 가 능성이 높다. 이러한 이유로 두 농약의 $\mathrm{RL}_{50}$ 이 6.9일 및 6.4일 로 나타나, 6 종의 농약 중 분해 및 소실이 가장 빠른 것으로 판단된다. 반면에 $\mathrm{RL}_{50}$ 이 12.2일 및 15.1 일로, 6종의 농약 중 상대적으로 감소속도가 느린 fluquinconazole $(\log \mathrm{P}=3.24$, $\mathrm{pKa}=0.9)$ 및 tetraconazole $(\log \mathrm{P}=3.56, \mathrm{pKa}=0.65)$ 은 침투가 능성이 가장 높은 농약이라 판단된다. 침투된 두 농약은 물관 부를 통하여 작물체 내에서 이동성이 커지며, 작물체 내에서 이 동성이 크기 때문에 두 농약은 작물 전체에 분배될 수 있고, 주 변 환경에 의해 분해 및 소실 가능성이 적을 수 있다. 또한 tetraconazole 및 fluquinconazole은 $\mathrm{pH}$ 4-9에서 수중 가수분해 에 대하여 매우 안정한 것으로 보고되는데, 물관부의 $\mathrm{pH}$ 는 약 5.5 로 tetraconazole 및 fluquinconazole이 6종의 농약 중 상대적 

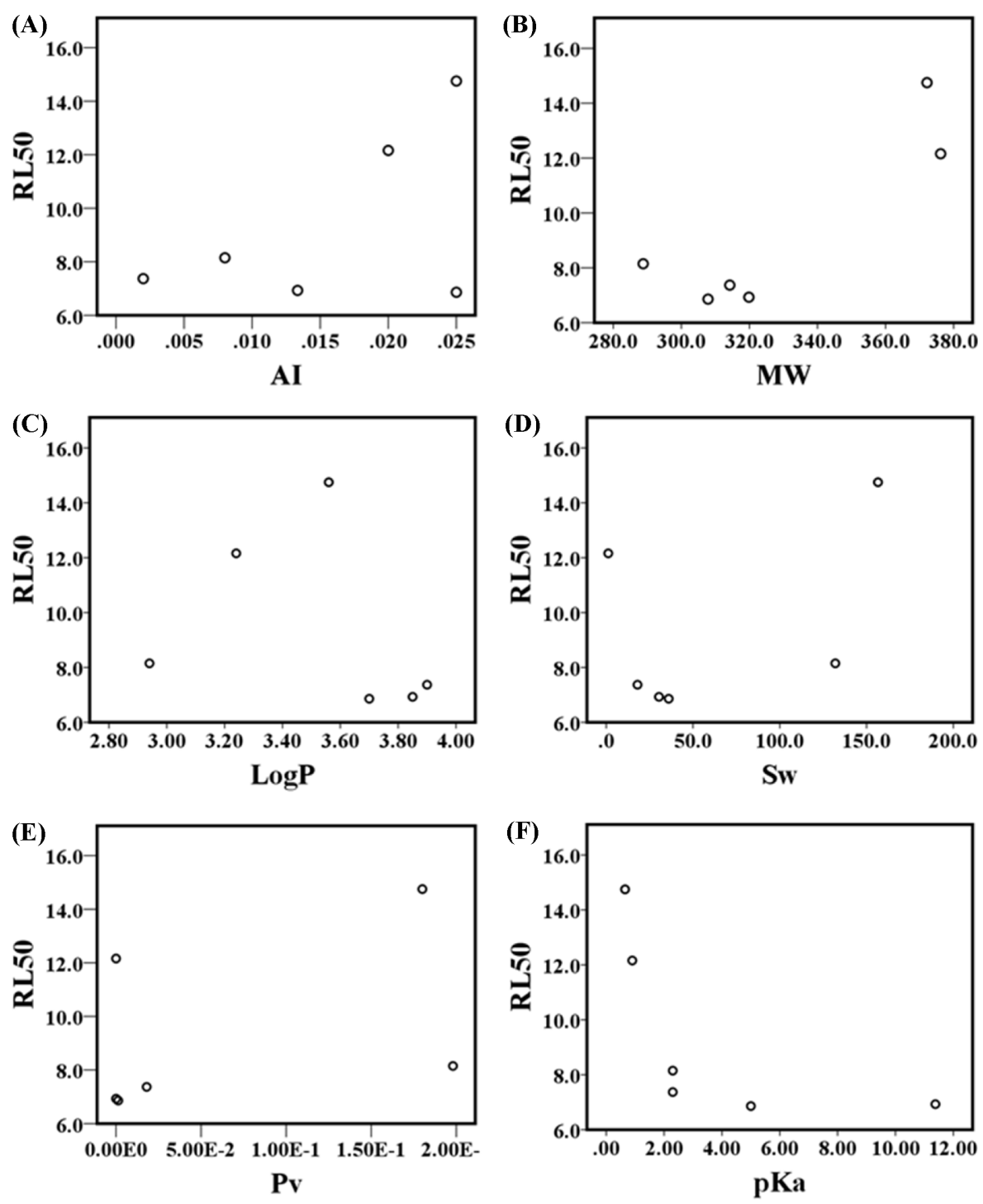

Fig. 2 Correlation analysis and scatter plot: $\mathrm{RL}_{50}$ vs. active ingredient (A), molecular weight (B), $\log \mathrm{P}(\mathrm{C})$, solubility in water (D), vapor pressure (E), and dissociation constant (F)

Table 6 Spearman rank-order correlation coefficient between $\mathrm{RL}_{50}$ and physicochemical properties of the 6 triazole fungicides in perilla leaf

\begin{tabular}{cccc}
\hline \hline $\begin{array}{c}\text { Physicochemical } \\
\text { property }\end{array}$ & $N^{\mathrm{a})}$ & $R^{2}$ & $p$-value \\
\hline $\mathrm{IC}^{\mathrm{b})}$ & 6 & 0.543 & 0.266 \\
$\mathrm{AI}^{\mathrm{c})}$ & 6 & 0.116 & 0.827 \\
$\mathrm{MW}^{\mathrm{d})}$ & 6 & 0.543 & 0.266 \\
$\log \mathrm{P}$ & 6 & -0.543 & 0.266 \\
$\mathrm{~S}_{\mathrm{W}}{ }^{\mathrm{e})}$ & 6 & 0.200 & 0.704 \\
$\mathrm{P}_{\mathrm{V}}{ }^{\mathrm{f}}$ & 6 & 0.257 & 0.623 \\
$\mathrm{pKa}^{\mathrm{g})}$ & 6 & -0.928 & $<0.01$ \\
\hline
\end{tabular}

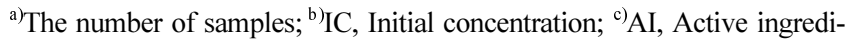
ent; ${ }^{\text {d) } M W, ~ M o l e c u l a r ~ w e i g h t ; ~}$

${ }^{\text {e) }} \mathrm{S}_{\mathrm{W}}$, Solubility in water; ${ }^{\mathrm{f}} \mathrm{P}_{\mathrm{V}}$, Vapor pressure; ${ }^{\mathrm{g}} \mathrm{pKa}$, Dissociation constant

\section{으로 분해 및 소실속도가 느린 것으로 판단된다.}

Table 1에서 pKa가 낮은 순으로 나열하면 tetraconazole< fluquinconazole $<$ hexaconazole $<$ myclobutanil $<$ tebuconazole $<$ metconazole으로 나타나며, $\mathrm{RL}_{50}$ 은 tebuconazole $<$ metconazole $<$ hexaconazole $<$ myclobutanil $<$ fluquinconazole $<$ tetraconazole 순으로 반감기가 길어진다. 따라서, $\mathrm{pKa}$ 가 낮을수록 침투성이 높아져 작물체 내에 오랫동안 잔류함으로써 반감기 높아지는 결 과가 도출되며, Table 6 및 Fig. 2 와 같이 $\mathrm{RL}_{50}$ 과 $\mathrm{pKa}$ 는 음의 상관 관계가 있는 것으로 판단된다.

\section{초 록}

들깻잎에 살포된 triazole계 살균제 6종에 대하여 생물학적 반 감기를 산출하고 분해 및 소실 속도를 확인하였으며, 통계분석 
으로 생물학적 반감기와 농약의 물리화학적 특성간의 상관관계 를 확인하였다. 확립된 분석법으로 6 종 농약의 회수율 시험 결 과 84.8-104.9\%로 잔류농약분석법 기준을 만족하였다. 들깻잎에 살포한 농약 6종의 생물학적 반감기는 first-order kinetics model으로 산출하였으며, 그 결과 6.4-15.1일로 나타났다. 산출 된 생물학적 반감기와 6종의 농약의 물리화학적 특성을 주성분 분석으로 상관성을 확인하였을 때, $\mathrm{pKa}, \log \mathrm{P}$ 및 생물학적 반 감기가 $\mathrm{PC} 1$ 에 영향을 받아 상관성이 있는 것으로 나타났다. Spearman rank-order correlation으로 생물학적 반감기와 물리화 학적 특성간의 상관계수를 산출하였을 때, 생물학적 반감기와 $\mathrm{pKa}$ 는 $R^{2}=-0.928, p<0.01$ 로 나타나, 생물학적 반감기는 $\mathrm{pKa}$ 와 상관성이 있는 것으로 나타났다.

Keywords 들깻잎 · 물리화학적 특성 · 살균제 · 생물학적 반 감기 · 통계분석

감사의 글 이 연구는 식품의약품안전처의 2019 년 소면적 재배 농산물의 농 약 잔류허용기준 설정 연구(과제번호: 00-19-8-064400)의 연구비 지원으로 수행된 결과의 일부이며 이에 깊은 감사 드립니다.

\section{References}

1. Jung YH, Kim JE, Kim JH, Lee YD, Im CH, Huh JY (2004) New Pesticides, Sigma Press Inc., Korea

2. Kim JY, Lee SM, Lee HJ, Chang MI, Kang NS, Kim NS, Kim HJ, Cho YJ, Jeong JY, Kim MK, Rhee GS (2014) Monitoring and risk assessment of pesticide residues for circulated agricultural commodities in Korea2013, J Appl Biol Chem 57(3): 235-242

3. Kim KJ, Kim DS, Heo SJ, Ham HJ, Hur JH (2013) Establishment or pre-harvest residue limit (PHRL) of emamectin benzoate during cultivation of amaranth. Korean J Pestic Sci 17(2): 77-83

4. Holland PT, Malcolm CP, Mowat AD, Rohitha BH, Gaskin RE (1996) Modelling of pesticide residues on fruit II: Persimmon. In Proceedings of the 49th New Zealand Plant Protection Conference, New Zealand, pp 192-197

5. Pfleeger TG, Fong A, Hayes R, Ratsch H, Wickliff C (1996) Field evaluation of the EPA (Kenaga) nomogram, a method for estimating wildlife exposure to pesticide residues on plants. Environ Toxicol Chem 15: 535-543

6. Galera MM, Vidal JLM, Gonzalez FJE, Garcia MDG (1997) A study of fenpropathrin residues in tomatoes and green beans grown in greenhouses in Spain. Pestic Sci 50: 127-134

7. Sadlo S (2000) Quantitative relationship of application rate and pesticide residues in greenhouse tomatoes. J AOAC Int 83: 214-219

8. Park DS, Seong KY, Choi KI, Huh JH (2005) Field tolerance of pesticides in the strawberry and comparison of biological half-lives estimated from kinetic models, Korean J Pestic Sci 9(3): 231-236

9. Zhao H, Xue J, Jiang N, Peng W, Liu F (2012) Dissipation and residue of fenpropidin in wheat and soil under field conditions. Ecotox Environl Safe 77: 52-56

10. Liu C, Qin D, Zhao Y, Pan C, Jiang S, Liu F (2010) Famoxadone residue and dissipation in watermelon and soil. Ecotox Environl Safe 73: 183188

11. Lee MH, Kim SH, Park GY, Shin GB, Kim JH, Kwon CH, Sohn JK, Kim JE (2007) Residual pattern of pesticide, chlorfluazuron in perilla leaves under plastic house, Korean J Pestic Sci 11(2): 106-116

12. Zhou, J, Zhang F, Li, Liu J (2016) Triazole fungicide tebuconazole disrupts human placental trophoblastcell functions. J Hazard Mater 308: 294-302
13. Choi SJ, Hwang IS, Cho TH, Lee JI, Lee IS, Yook DH, Park WH, Kim MS, Kim GH (2015) Analysis of hexaconazole in agricultural products using multi class pesticide multiresidue method. J Food Hyg Saf 30(4): 366-371

14. Seong KC, Cho JR, Moon JH, Kim KY, Suh HD (2003) Effect of Triazole Chemicals on Bolting Retardation of Chinese Cabbage (Brassica pekinensis) in Spring Cultivation. J Kor Soc Hort Sci 44(4): 434-437

15. Kang JG, Hwang JI, Lee SH, Jeon SO, Kwak SY, Park JH, Kim JE (2016) Residual patterns of fungicides fludioxonil and metconazole in different parts of wheat. Korean J Pesti Sci 20(4): 341-348

16. Hwang LH, Cho IS, Kim MJ, Cho TH, Park YH, Park HW, Park KA, Kim HJ, Kim MS (2011) Removal of pesticide residue during the preparation of Baechu Kimchi and perilla leaf pickle. J Fd Hyg Safety 28(4): 403-409

17. MFDS(Ministry of Food Drug and Safety) (2016) Korean food standards codex pesticide analytical manual 4th ed., Ministry of Food and Drug Safety, Korea

18. Jeon SO, Hwang JI, Kim TH, Kwon CH, Son TU, Kim DS, Kim JE. (2015) Residual patterns of insecticides bifenthrin and chlorfenapyr in perilla leaf as a minor crop. Korean J Environ Agric 34(3): 223-229

19. Jeong HR, Noh HH, Lee JY, Park HK, Jin MJ, Kim JC, Hong SM, Kyung KS (2017) Residual characteristics and safety assessments of bifenthrin, carbendazim and metconazole in angelica gigas nakai. Korean J Pesti Sci 21(1): 97-105

20. Stock D (1996) Proc Brighton Crop Protection Conference- Pests and Diseases, Brighton. pp. 791-800. British Crop Protection Council, UK

21. Zabkiewicz J (2007) A. Spray formulation efficacy- holistic and futuristic perspectives. J Crop Prot 26: 312-319

22. Ahn SY, Kim KD, Lee JN, Inn JS, Nam CW, Jung JC, Lee EH (2008) Removal efficiency of pesticide residues in Chinese cabbage produced in highland by washing. Kor J Hort Sci Technol 26(4): 400-405

23. Hwang JI, Kim JE (2013) Residue patterns of fungicides, flusilazole and myclobutanil in apples. Current Research on Agriculture and Life Sciences, 31(4): 272-279

24. Beods C, Rousseau-Djabri MF, Loubet B, Durand B, Flura D, Briand O, Barriuso E (2010) Fungicide volatilization measurements: inverse modeling, role of vapor pressure, and state of foliar residue. Environ Sci Technol 44: 2522-2528

25. Zhao H, Xue J, Jiang N, Peng W, Liu F (2012) Dissipation and residue of fenpropidin in wheat and soil under field conditions. Ecotox Environ Safe 77: 52-56

26. Rosendahl I, Laabs V, Atcha-Ahowe C, James B, Amelung W (2009) Inseticide dissipation from soil and plant surfaces in tropical horticulture of southern Benin, West Africa. J. Environ. Monit 11: 1157-1164

27. Kim SS, Kim TH, Lee SM, Park HR, Park DS, Lim CK (2008) Mobility of pesticides from soil in different slope by simulated rainfall under field conditions. Korean J Pesti Sci 12(1): 24-33

28. Noh HJ, Yu JY. (2016) Multivariate Analysis Theory and Practice using SPSS \& EXCEL. pp. 396-400. First ed. Jiphill media, Korea

29. Lee SJ (2015) Big data analysis using principal component analysis. J Korean Inst Intell Syst, 25(6): 592-599

30. Satchivi NM, Stoller EW, Wax LM, Briskin DP (2006) A nonlinear, dynamic simulation model for transport, and whole plant allocation of systemic xenobiotics following foliar application. IV: Physicochemical properties requirements for optimum absorption and translocation. Pestic Biochem Phys, 84: 83-97

31. Reuveni M. (2003) Activity of the new fungicide benthiavalicarb against Plasmopara viticola and its efficacy in controlling downy mildew in grapevines. Eur J Plant Pathol 109: 243-251

32. White AD, Heaverlo CA, Owen MDK. (2002) Evaluation of methods to quantify herbicide penetration in leaves. Weed Technol, 16: 37-42

33. Briggs GG, Bromilow RH (1994) Interactions between Adjuvants, Agrochemicals and Target Organisms. pp. 1-26. Springer-Verlag Berlin Heidelberg New York, USA 
34. Stock D, Holloway DJ, Grayson BT, Whitehouse P (1993) Development of a predictive uptake model to rationalize selection of polyoxyethylene surfactant adjuvants for foliage-applied agrochemicals. Pestic Sci 37: 233-245

35. Lehoczki-Krsjak S, Varga M, Szabo-Hever A, Mesterhazy A (2013) Translocation and degradation of tebuconazole and prothioconazole in wheat following fungicide treatment at flowering. Pest Manag Sci, 69: 1216-1224

36. Schermerhorn PG, Golden PE, Krynitsky AJ, Leimkuehler WM (2005) Determination of 22 triazole compounds including parent fungicides and metabolites in apples, peaches, flour, and water by liquid chromatography/ tandem mass spectrometry. J AOAC Int, 88: 1491-1502 